\title{
CULTIVATING HUMAN CAPABILITIES IN VENTURESOME LEARNING ENVIRONMENTS
}

\author{
Pádraig Hogan \\ Education Department \\ National University of Ireland, Maynooth
}

\begin{abstract}
The notion of competencies has been a familiar feature of educational reform policies for decades. In this essay, Pádraig Hogan begins by highlighting the contrasting notion of capabilities, pioneered by the research of Amartya Sen and Martha Nussbaum. An educational variant of the notion of capabilities then becomes the basis for exploring venturesome environments of learning: environments that are hospitable to the cultivation of such capabilities among students and their teachers. In this exploration Hogan emphasizes disclosing the kinds of relations that constitute such environments. In particular, he identifies four kinds of relations and investigates the interplay among them. In the second part of the essay, Hogan reviews an ongoing research project in Ireland that has been promoting such environments in postprimary education: Teaching and Learning for the 21st Century. Although the project avoids proffering universal claims about "what works," its rationale and conduct nevertheless call policymakers' attention to what has worked and to the reasons why.
\end{abstract}

\section{INTRODUCTION}

I would like to begin this essay by exploring a pedagogical variant of the notion of capabilities, as articulated by Amartya Sen and Martha Nussbaum, and by distinguishing it clearly from that of competencies. ${ }^{1}$ The familiar notion of competencies directs attention to the mastery of measurable skills and performances. That of capabilities, especially as developed by Nussbaum, directs attention to the progressive cultivation of human capacities to think critically, to attend with discernment, to anticipate with circumspection, to act with moral insight and energy, and so on. Nussbaum has identified a list of ten key capabilities, ranging from that of being able to live a life of normal length at the basic end, to that of being able to participate in an effective way in the choices that govern one's life at the more developed end..$^{2}$ Sen is hesitant about identifying a specific list of capabilities. He stresses instead - as a pioneering kind of economist the departure of a capabilities approach to human welfare from more traditional utilitarian approaches (for example, Benthamite) or resource-based approaches (such as gross domestic product [GDP] per head). The more general nature of Sen's stance is reaffirmed in one of his most recent works: "In contrast with the utility-based or resource-based lines of thinking, individual advantage is judged in the capability approach by a person's capability to do the things he or she has

1. Amartya Sen and Martha C. Nussbaum, The Quality of Life (Oxford: Clarendon Press, 1993); Martha C. Nussbaum, Women and Human Development: The Capabilities Approach (Cambridge: Cambridge University Press, 2000); and Amartya Sen, The Idea of Justice (Cambridge, Massachusetts: The Belknap Press of Harvard University Press, 2009).

2. Nussbaum, Women and Human Development, $78 \mathrm{ff}$. 
reason to value. ${ }^{\prime 3}$ But Sen also credits different developments of the capabilities approach, and specifically Nussbaum's:

The capability approach is a general approach, focusing on information on individual advantages, judged in terms of opportunity rather than a specific "design" for how a society should be organized. A number of very distinguished contributions have been made by Martha Nussbaum and others in recent years on matters of social assessment and policy through powerful use of the capability approach. ${ }^{4}$

Sen's endorsement in this passage of investigations by others into the promise of a capabilities approach in different fields of research and human endeavor expands and refines the possibilities for inquiry. In the philosophy of education such investigations have been carried out by Geoffrey Hinchliffe, Lorella Terzi, and others. ${ }^{5}$ Mindful of these developments, I see particular merit in exploring the potential of a capabilities approach to release educational thought and action from the constricting legacy of a generation or more of preoccupation with competencies. In an educational sense, capabilities can be understood as those human accomplishments, promoted by deliberate learning, that enable informed choices to be made and judicious action to be taken, particularly in unfamiliar or challenging circumstances.

I am keen to illustrate in my contribution to this symposium that pedagogy, in an age of increasing plurality and uncertainty, needs to stress capabilities more than competencies, and that educational policy needs to support this strongly. In making this case I will elucidate the idea of venturesome environments of learning. I will also challenge the kinds of pedagogical attitudes, practices, and professional cultures that attachment to a competencies policy has promoted in schools internationally in recent decades. Ultimately, however, I will stress the necessity to take a step beyond critique because education is first and foremost a constructive practice - as distinct from a phenomenon available for critical scrutiny and analysis.

\section{Venturesome Learning Environments and Their Domains of Relations}

The phrase "venturesome learning environment" refers to something that lies at the heart of education when viewed as a distinct practice in its own right. First, the phrase refers to a learning environment where it is safe for each participant to venture his or her considered thoughts, without fear of belittlement if what is ventured is faulty. Such an environment is particularly hospitable to new

3. Sen, The Idea of Justice, 231.

4. Ibid., 232.

5. Geoffrey Hinchliffe and Lorella Terzi, eds., "Capabilities and Education," special issue of Studies in Philosophy and Education 28, no. 5 (2009).

PÁDRAIG HOGAN is Senior Lecturer in the Education Department, National University of Ireland, Maynooth, at Maynooth, Co. Kildare, Ireland; e-mail <padraig.hogan@nuim.ie>. His primary areas of scholarship are high quality learning environments, philosophical hermeneutics, and continuing professional development for teachers. 
questions, new perspectives on the matter under exploration, and new possibilities for learning. There is a shared expectation, then, that such contributions will be freely and purposefully ventured.

Second, the phrase refers to the quickening of mind and heart that occurs among learners where particular practices of learning have become "conversational," in Michael Oakeshott's sense of the word: where "thoughts of different species take wing and play around one another, responding to each other's movements and provoking one another to fresh exertions. ${ }^{\prime \prime}$ This reference to "different species" of thought highlights the point that genuine conversation acknowledges from the start the plurality of the human condition, and that plurality must be allowed its due scope in the conduct of educational endeavors.

Third, in the medium to longer term, the phrase refers to a distinct kind of ethical and imaginative landscape that accompanies fruitful experiences of learning: namely those experiences through which particular capabilities and fluencies are brought to progressively higher levels of accomplishment. ${ }^{7}$ John Dewey used the phrase "collateral learning" to highlight the overlooked but lasting influence exerted by the attitudes that accompany any instance of teaching and learning. ${ }^{8}$ But this collateral dimension — for example, the enduring likes and dislikes quietly picked up during a geometry or French lesson - is itself influenced by the imaginative color of those regions to which thoughts and efforts are memorably beckoned during the lesson. It may be influenced also by the forgettable quality of thoughts that remain earthbound through lackluster, predictable teaching practices.

Informal learning environments - in homes, in workplaces, in recreational contexts-could well be venturesome in the sense described. But here I want to emphasize that formal learning environments need to be so, at least in some meaningful degree, to be properly described as educational. It is with formal environments of learning that I am centrally concerned here. These can, of course, range from preschool to continuing education to graduate school.

Not surprisingly, this emphasis on the quality of learning environments brings pedagogical practices and relations to center stage. It is important to acknowledge from the beginning that such practices and relations are always socially and historically situated. That is to say, pedagogical practices and relations are always subject to what Hans-Georg Gadamer called an "effective history" of influences (Wirkungsgeschichte)..$^{9}$ These include influences from policy measures,

6. Michael Oakeshott, "The Voice of Poetry in the Conversation of Mankind," in Rationalism in Politics and Other Essays (1962; repr. London: Methuen, 1981), 198.

7. For a more detailed investigation of this point, see Pádraig Hogan, "The Ethical Orientations of Education as a Practice in Its Own Right," Ethics and Education 6, no. 1 (2011): 27-40.

8. John Dewey, Experience and Education (1938; repr. New York: Macmillan, 1995), 48.

9. Hans-Georg Gadamer, Truth and Method, trans. Garrett Barden and John Cumming (London: Sheed and Ward, 1975), 10-19. 
from administrative procedures, from parental pressures, from gendered assumptions, from preconceived ideas about social class or ethnic background, from the tenor of responses by students and teachers, from examination requirements, and so on.

Many of these influences are constricting ones, as some of the other contributions to this symposium emphasize. Teachers as practitioners are often frustrated by such constrictions. But many teachers may have become so habituated in inherited attitudes and practices as to be unaware, or only partially aware, of what possibilities are being constricted, or of how relations of learning have become systematically distorted. Christiane Thompson's perceptive observations on the "decomposition" of pedagogical relations in the third part of her article in this symposium are pertinent in this connection. ${ }^{10}$

In looking more closely at the characteristics of venturesome learning environments, I would like to identify, from the standpoint of teaching as a distinct kind of practice, four broad domains of relations. These are not readymade, separate categories. Rather, they are four domains of human capability that, when they interweave productively, enable venturesome learning environments to be fostered and sustained. Every pedagogical relation involves such domains, though where educational practice is inadequately understood, or is carried out in an instrumentalist way, both the inescapability and the significance of this point are likely to be missed. The four domains are (1) the teacher's relations with the subject or material being taught; (2) the teacher's relations with his or her students; (3) the teacher's relations with colleagues, parents, educational authorities, and a wider range of others; and (4) the teacher's relation to him- or herself, within which the character and significance of the other three domains are decided. ${ }^{11}$

In all four there is, properly speaking, a particular kind of love. To speak with Hannah Arendt, one might rightly call this a love of engagement with the world. ${ }^{12}$ This is a kind of love that gives itself in different ways to the betterment of humankind's lot and to enrichments of human experience. It contrasts with, without excluding, more ascetic forms of love that leave the world much as it is and concentrate mainly on worship and veneration of the divine. Where teaching is concerned, love of engagement with the world involves a desire and a will to become fluent, as a practitioner, in four specific kinds of engagement, each of which mingles with the others in cultivating venturesome learning environments. I would now like to explore in a preliminary way each of the four.

10. Christiane Thompson, "Evaluations and the Forgetfulness of Pedagogical Relations: Remarks on Educational Authority," in this issue.

11. This fourfold characterization draws on an analysis I first carried out in Pádraig Hogan, The New Significance of Learning: Imagination's Heartwork (London: Routledge, 2010), chap. 4.

12. Hannah Arendt, "The Crisis in Education," in Between Past and Future (Harmondsworth, UK: Penguin, 1993), 196. 


\section{Teachers' Relations with Their Teaching Subjects}

In the teacher's relations with a subject - economics, physics, history - the heart of the matter is bypassed if these relations are mainly seen as an issue of competence in a body of knowledge or skills, ready and waiting for transmission. If the subject in question is not alive and communicative within the teacher's ongoing engagements with it, it is unlikely that students will experience the worlds of possibility, challenge, and discovery to be opened up by the subject. That is to say, the teacher needs to build relations to the subject as to a neighborhood, or range of neighborhoods, in which he or she has come to feel at home, but not in the sense of a cosy repose for thought and action. Such neighborhoods are characterized not by horizons that are everywhere familiar, but by invitations that beckon and demands that lead quite beyond such horizons. Yet, they remain neighborhoods into which students must be invited ever anew, evoking and sustaining the students' genuine potentials and energies. This is very much a labor of love, and of a perceptive, persevering kind.

But even where a teacher's relations with a particular subject, or range of subjects, are richly alive, the character of these relations might still be restrictive in an educational sense. Becoming progressively more at home in the imaginative worlds opened up by a subject one loves can bring its own difficulties if one is to be pedagogically capable as a teacher. These might colloquially be described as difficulties in "talking to the locals": the increasingly pluralist multitudes of pupils who populate classrooms, but who also wander more familiarly amid the busy offerings of twenty-first-century entertainment industries. Some practical strategies for tackling such difficulties are referred to in the second part of this essay. The major research project reviewed there represents a large-scale effort to enhance the capabilities of both students and teachers by making the learning environments they share more participatory and venturesome.

But another kind of criticism can be brought against an engrossed love of one's subject. This is the claim that such a love gives the upper hand to conservative influences over more critical and questioning ones in a teacher's beliefs and attitudes. Variants of critical theory, from the work of Jürgen Habermas in his early writings to that of Terry Eagleton, would charge that inheritances of learning, no matter how cherished they might be, are never without embedded presuppositions. Such presuppositions, critical theory points out, often involve institutionalized distortions and invidious distinctions that silence rather than empower marginalized voices.

Criticisms such as these highlight a few key points if a teacher's relations with his or her teaching subjects are to be healthy and enriching. In the first place, such relations involve personal commitments, or labors of love. That is to say, they are essentially more than, and different from, the technical notion of "up-skilling." Such labors are committed to enabling others to share in the inherent benefits, not merely the external rewards, of a particular human pursuit. For instance, if I am a teacher of history, the external rewards to be gained by my students include high grades on their exams, commendation from teachers and parents, and perhaps a 
coveted place in a college program. But such rewards apply in other subjects as well. The inherent benefits are those that enable my students to discover something of the historian in themselves: to open up the intriguing world of motivations, aspirations, and value conflicts that lie beneath the data of historical record; to appreciate something of the shifting interplays ever at work between forces of continuity and forces of change; to understand how influences from the past both disclose and constrain the possibilities of the present and the future. In short, the inherent benefits mark, in each case, an unforced calling forth of a student's own capabilities. This recognizes that the profile of potentials differs from one person to the next, but also that a plurality of possibilities, as well as being a feature of groups, is a feature of human experience as it unfolds in each individual.

Second, there is a marked contrast here with conventional conceptions of a teacher's fluency in a subject. Conventional conceptions tend to view fluency less as the yield-to-date of a labor of love and more as a competency. The underlying understanding of conventional conceptions of fluency is mainly technical in character. In other words, there is an assumption that fluency in all essential respects can be captured by tests and indexed by the results of such tests. Such an understanding can present itself as innocent of any ideological baggage, and thus as an important virtue of procedure in workplace cultures pervaded by quantitative analysis and evaluations. But this species of understanding remains largely blind to the insight - common in different ways to John Dewey, Martin Heidegger, Ludwig Wittgenstein, and many other philosophers - that no form of human understanding is without decisive presuppositions, implicit interpretations, and predisposing "fore-conceptions."13

Third, and more positively, a love of one's subject that is pedagogically productive is in itself an active, sometimes even a turbulent love. It includes a recurrent to-and-fro in one's own experience between a receptive openness to the voices that speak from inheritances of learning and a more critical interrogation of such voices. It contributes in a particular way to a deepening of self-understanding that will be reviewed more closely in my discussion of the fourth domain of relations. I also take up the import of this point for policy priorities in the professional development of teachers in the second part of the essay.

\section{Teachers' Relations with Their Students}

Teachers' relations with students are more accurately understood as a lively interplay than as any kind of transmission. One might say that they are an everrenewed dialogue, enabling the students to experience something genuine of the imaginative neighborhood opened up by the teacher. But this would be wrong, or at least inadequate. It would be rather one-sided, overlooking the point that an educational dialogue opens up a new imaginative neighborhood, constituted

13. "Fore-conception" is a translation of Heidegger's term Vorgriff, which he elucidated in section 32 of Being and Time - together with Vorhabe (fore-having) and Vorsicht (fore-sight) — in presenting his argument that human understanding is interpretive from the start. See Martin Heidegger, Being and Time, trans. John Macquarrie and Edward Robinson (Oxford: Basil Blackwell, 1973), 191-192. 
and colored by the contributions of the various participants. Granted, the teacher may have frequently traveled these regions before in his or her own relations with the subject. But if the teacher's relations with the students are genuinely dialogical, then the teacher travels the same path anew and finds that it becomes a somewhat different path through a previously familiar landscape, but now with some unexpected features.

Crucial to such relations, then, is that they seek to enable students to become active and responsible participants in their own learning. For students this kind of enablement means taking uncoerced steps toward the discovery of their own potentials and limitations in response to the voices and challenges that engage them in a buoyant community of learning. In other words, as touched on briefly already, it involves them in discovering something of the geographer in themselves, or of the biologist, or mathematician, or linguist; or discovering something of their own aptitude for designing and making - say, in wood, in textiles, or in other materials; or discovering something of a literary, scientific, or religious sensibility in themselves. This can of course sometimes be a discovery of limitation. Take, for instance, the emergent recognition that one does not have a strong aptitude for mathematics, or languages, or some other subject that one may still have to study as a "core subject" until the minimum school-leaving age. Facing up to this recognition, while continuing to give one's best efforts to the subject in question, is itself a capability of primary importance, and one that is unlikely to be cultivated where overt or unremarked forms of belittlement feature regularly in learning environments. This is not to make an argument for specialization at an early age, nor is it to advocate streaming, or tracking. Rather, it is to say that plurality within learning environments needs to be sustained, at least until the students' mid-teens, by greater differentiation in pedagogical practices. Such practices would involve the students themselves, as far as possible, as active and responsible participants in the learning environments that constitute their daily experiences in school. Again, this is an issue to be taken up in the second part of the essay, at a level where research and practice become joined.

Where learning environments are predominantly compliant or authoritarian, passive or aggressive, it is unlikely that relations between teachers and students will be marked by dialogue. Pedagogical dialogue is a form of persevering action. It is marked by an enduring ethical commitment to building and sustaining the kinds of relations that make learning environments places where it is safe to venture and rewarding to listen. This kind of commitment is very necessary where the best efforts of students continually come up with wrong answers, or a series of dead-end paths, or where the teacher makes an error of judgment. It is even more necessary where frustrations in a learning environment lead to outbursts of acrimony, or where a more deep-seated resentment on the part of some students continually threatens to subvert the learning ethos. In such circumstances, insights and actions that may run quite counter to the intuitions lodged in traditional pedagogies are called for. For instance, as Nicholas Burbules puts it in his study Dialogue in Teaching, "maintaining the relational conditions 
for further discussion is frequently more important, in the long run, than settling the specific question at hand."14

It is important to stress that it is the realization, or bringing about, of such relations - among students themselves as well as with their teachers that allows environments of learning to become properly fertile. This realization remains inescapably incomplete, however. It is the ever-partial attainment of an aim-in-view. It identifies a crucially important human capability, but not one that can be accomplished with an assured finality. Moreover, it remains continually vulnerable to setbacks, distortions, and even collapse. As Morwenna Griffiths's article in this issue illustrates, pedagogical relations in group settings are particularly susceptible to contingencies, favorable or adverse. ${ }^{15}$ Recognition of this contingent dimension, however, sits well with a conception of teaching and learning that regards it as conversational. The teacher of course carries a central responsibility for how such conversation is experienced in a classroom, or school laboratory, or other formal learning environment. But the points just made are an important reminder that the most fruitful conversations are not something that can be conducted according to a predesigned pattern. Rather, they are something we "fall into" when the circumstances are hospitable, or, in the case of learning environments, where they are as far as possible made hospitable through insightful efforts. It is thus that thoughts can "take wing," as Oakeshott says, and that learning environments can take on their own unforced momentum and tenor.

\section{Teachers' Relations with Colleagues, Authorities, Parents, and THE Wider Community}

Where relations with colleagues, parents, educational authorities, and others in the wider society are concerned, this domain, like the two just discussed, could readily be subdivided. Moreover, critical analysis of this domain illustrates how ubiquitous issues of power are in it. The history of education in Western civilization is replete with examples of unequal power relations as an inherited and renewed norm: between older and younger teachers, between teaching colleagues in pursuit of professional advancement, between teachers and school managements, between teachers and parents, between teachers and policy authorities, and so on.

But critical analyses of this kind fall short of their own best purposes if they neglect to analyze the interplay of power with other human motives. The shortfall is more serious if analysis fails to make explicit the question implied in all critique of human practices: Critique for the sake of what? Recall here that education is a practice, as distinct from a natural phenomenon or a biological process. It is when we engage with the practical question "critique for the sake of what?" that the

14. Nicholas C. Burbules, Dialogue in Teaching: Theory and Practice (New York: Teachers College Press, 1993), 144.

15. Morwenna Griffiths, "Critically Adaptive Pedagogical Relations: The Relevance for Education Policy and Practice," in this issue. 
real possibilities of this third domain of relations come properly into view. To put this coming-into-view succinctly: one's teaching colleagues are rightly regarded as sources of constructive criticism and ideas; parents and guardians are properly seen as supportive partners; educational authorities as potential sources of coherent and accountable policy; and the public mainly as a body whose trust is necessary but must be earned. This, I should stress, is less a theory of professional relations than an uncovering of the kind of work that actually needs to be done in the everyday conduct of professional practice.

None of this is to ignore the very real kinds of acrimony referred to in the second last paragraph, nor is it to overlook the fact that even the best instances of a practice will probably fall short of the ideals mentioned in the last one. Jockeying for advantage, the venting of personal powers and perks, and the furthering of one's own way are features of most workplaces. But to make these the controlling forces in elucidating the conduct of relations in any socially beneficial practice is to disfigure the practice itself. Or it is to describe a practice that has already been disfigured. Being critically alert to how such disfigurements can become institutionalized provides an invaluable vantage point to teachers. In the first place, it helps to clarify the coherence of teaching as a practice and to challenge the discouraging idea that education is an "essentially contested concept."16 Second, such alertness discloses navigational markers to teachers who are keen to work collegially in building and sustaining learning environments that are hospitable to venturing. A central insight here is that teaching is seen less as instruction carried out by individuals in isolation from each other, and more as a cooperative promotion of learning by a diverse group of colleagues. Such diversity will mean wide differences of outlook in matters political, economic, religious, and so on. Notwithstanding these, the cooperative efforts of teachers as educational practitioners are properly dedicated to something coherent amid this diversity. In a sentence, that coherence lies in promoting a profusion of human flourishing through promising and defensible practices of learning. Recognizing the importance of this, the cultivation of collegial relations that contribute to venturesome learning environments played a central part in the research project that will be reviewed in the second part of this article.

\section{Teachers' Relations to Self}

This fourth domain of relations can also be described as the teacher's selfunderstanding. Here the other three relations come together - profitably or otherwise - to orient in one way or another the teacher's thinking and actions. For instance, my relation as a teacher to the subjects I teach might be a cherished one that continually attracts me to new encounters. But I might be disposed in a

16. David Carr has criticized a strong tendency in philosophy of education to accept a view of education as something "essentially contested." Carr writes, "it is almost routinely assumed or claimed that 'education' is a 'contested' concept: that is, it is held that education is invested — as it were, 'all the way down' - with socially constructed interests and values that are liable to diverge in different contexts to the point of mutual opposition." David Carr, "Education, Contestation, and Confusions of Sense and Concept," British Journal of Educational Studies 58, no. 1 (2010): 89-104. 
different way toward my students, frequently resenting their lack of appreciation of my efforts. In this case the very richness of the first domain of relations could possibly become a refuge for the teacher from the second domain. That refuge may even become a prison if the world into which the teacher is drawn offers ever fewer ideas or possibilities for sharing its treasures with those who are still largely strangers to it. On the face of it, this kind of distortion of the teacher's self-understanding is occasioned by an exclusive kind of academic love. From a pedagogical perspective, however, it is more accurate to say that the distortion occurs where an exclusive form of love becomes more than that: where it becomes exclusionary. In other words, the teacher's relations with the students are such, or have become such, that the teacher sees most if not all of them as unworthy of entry to the riches of the world in question, or as incapable of meeting even the rudimentary demands for entry. Or the teacher sees little possibility of recasting his or her own presentations of the subject so that its demands might in some way become negotiable by the students. Thus the teacher fails to see that his or her authority as teacher has to be earned, as illustrated, for instance, in Zdenko Kodelja's contribution to this symposium. ${ }^{17}$

This kind of intractability in the teacher's self-understanding straddles the first and second domains of relations (relation to subject and relation to students). A common way of viewing the kind of difficulty faced by the teacher here is to describe it as lack of "pedagogical content knowledge," to use a well-known phrase associated with Lee Shulman. Pedagogical content knowledge, in Shulman's own words, refers to "the blending of content and pedagogy into an understanding of how particular topics, problems, or issues are organized, represented, and adapted to the diverse interests and abilities of learners, and presented for instruction. ${ }^{\prime 18}$ As a particular form of know-how, pedagogical content knowledge furnishes many ideas and strategies for planning, illustrating, monitoring, giving and receiving feedback, and other aspects of a teacher's practice. It marks a decisive advance in the world of educational research. Yet, for all that, it seems more a possession than a disposition: a form of having as distinct from a way of being and acting. By contrast, the case I am arguing here involves an ontological shift of emphasis: from the possession and deployment of understanding and skill to more original and challenging ways of being human, and of relating to ideas and people.

The investigation of a research and development project in the second part of this essay will take up in a practical context the philosophical arguments I have been advancing here about venturesome learning environments. More particularly, in analyzing this project I will review some findings on the kinds of relations that cultivate human capabilities in such environments. From its early days, this project was informed by specific philosophical ideas. But it was also keen to revise

17. Zdenko Kodelja, "Authority, the Autonomy of the University, and Neoliberal Politics," in this issue.

18. Lee S. Shulman, "Knowledge and Teaching: Foundations of the New Reform," in The Wisdom of Practice (San Francisco: Jossey-Bass, 2004), 228. 
and refine such ideas, thus providing them with a stronger practical warrant and making them more robust candidates for the professional commitment of teachers and the attention of educational policymakers.

\section{The Possible and the Practical: Research on Learning Environments in a Policy Context}

Teaching and Learning for the 21 st Century (TL21 for short) is the name of a large-scale research project that was launched in December 2003 by the National University of Ireland, Maynooth (NUIM), and fifteen postprimary schools, five in each of three clusters: urban, suburban, and rural. An interim report, titled Voices from School, was published in 2005 and the final report on the active phase of the project, titled Learning Anew, was published in 2008. ${ }^{19}$ The project then entered a dissemination phase, called the TL21 Transfer Initiative, which ran from 2008 through 2012. This later phase involved a larger number of schools, organized in clusters around five government-funded education centers for continuing professional development (CPD). These education centers have become partners in the TL21 Transfer Initiative. ${ }^{20}$ The project also involved periodic discussions on the part of researchers with policymaking and managerial bodies in Irish education. This latter dimension has been crucial, not least because it has been an experience of reciprocal learning relations that has increasingly embodied many of the features explored in this essay. In fact without work on building such relations, which can of course sometimes hit a discordant note, it is difficult to see how trust and influence can grow between research and policymaking.

The two main aims of the TL21 project, and equally of the TL21 Transfer Initiative, have been (1) to strengthen postprimary teachers' capabilities as the authors of their own work, and (2) to enable postprimary students to take a more active and responsible role in their own learning. The main interventions of both the TL21 project and the Transfer Initiative have been providing CPD workshops for teachers, participatory in nature and organized in a linked sequence over twoyear time spans. For those participating in the workshops, there is an optional accreditation track. Those who choose this option can proceed to a postgraduate degree by carrying out a series of action research assignments focused on their own practice.

In the first series of workshops, some notable patterns quickly manifested themselves in the professional attitudes and practices of the participating teachers.

19. Pádraig Hogan, Anne Brosnan, Bernadette de Róiste, Alec MacAlister, Anthony Malone, Nigel Quirke-Bolt, and Greg Smith, Learning Anew: Final Report of the Research and Development Project "Teaching and Learning for the 21st Century, 2003-07" (Maynooth: Education Department, National University of Ireland, Maynooth, 2008), www.nuim.ie/TL21. The interim report, Voices from School (2005), was prepared by the same authors and also published by the Education Department of the National University of Ireland, Maynooth. The former work, Learning Anew, will be cited in the text as $L A$ for all subsequent references.

20. There are thirty education centers in Ireland, an average of just over one per county. They are funded by the national government and their primary purpose is the provision of CPD courses for teachers. 
These patterns were evident in each of the domains of learning relations that I have identified here. Taking each domain in turn, the patterns were as follows.

First, as regards teachers' relations to the subjects they were teaching, many of the initial participants maintained a lively personal interest in developments in their subjects. Yet too often that interest remained in a different compartment from their own work with their students in these subjects. Commercially prepared textbooks and other resources in the different subjects were a prevailing influence on both what was taught and how it was taught. ${ }^{21}$ At the outset of the project, teachers' attitudes and practices frequently revealed a relation to their subjects that seemed unduly influenced by what they perceived the examination system to reward. Teachers thus tended to concentrate on a narrow range of achievements in the subject in question (for example, in mathematics, science, English, Irish, and so on), springing mainly from rote learning and drill-and-practice teaching ( $L A$, 5-6). Such capabilities as were being cultivated were all too often conformist in character and tended to neglect the inherent benefits of the subject.

Second, where relations with students were concerned, for the most part the participating teachers enjoyed good relations with their students. But they hardly ever discussed their pedagogical ideas and practices with students. Moreover, rarely did they involve students in anything other than routine practices of learning. Such practices were carried through in efficient but predictable ways and were seldom evaluated afterward by the teachers $(L A, 5-6)$.

Third, the lack of discussion with students about how teaching and learning were to be planned and experienced was also evident as a prevailing pattern in teachers' relations with colleagues. Such relations were generally good and topics such as sport, family, and current affairs featured daily in conversations between teaching colleagues, as did incidents of misbehavior among students. But only occasionally were there professional discussions about the ideas that shaped their own thoughts and actions as practitioners.

Finally, at the beginning of the research project features such as these described in the last three paragraphs disclosed a prevalent self-understanding among teachers that was more acquiescent than questioning, more individualist than professionally collegial, more domesticated than venturesome.

Against this background I want to turn now to some central findings from the TL21 project, including its dissemination phase, the TL21 Transfer Initiative. I will highlight the kinds of changes in professional attitudes and practices, and in environments of learning, that it succeeded in promoting. The findings are drawn chiefly from the final report on the research-intensive stage of the project, Learning Anew.

First of all, to begin with the students, the use of new teaching and learning strategies - mainly from the assessment for learning family - brought about significant improvements in students' attitudes toward their work and also

21. Hogan et al., Voices from School, 6, 25, 27, 33, 36, 42, and 51. 
promoted their active involvement in that work. When properly availed of, assessment for learning approaches necessarily involve a discerning provision of constructive feedback to students. In fact, the adept use of such approaches can hardly fail to influence for the better the reciprocal relations of teachers and students. Moreover, we discovered that their regular use can make the enhancement of capability, both for students and teachers, an enduring feature of classroom environments. The kinds of changes that were most evident among students in the project's schools were a decrease in student-initiated conflicts with teachers; greater cooperation between students in group work and pair work; more positive attitudes toward learning among students; better practices of learning, including improved completion of homework; and better attendance rates in some instances where attendance rates were poor $(L A, 41-59)$.

Second, where the participating teachers were concerned, some found that their initial attempts in using new approaches were resisted by students. Here the project's workshops and informal networking provided valuable opportunities for teachers to share with each other the challenges they were experiencing and to identify possible solutions. It became clear that the best improvements in students' learning were recorded where teachers began with just one or two changes in approach and subsequently introduced others in a gradual way. These incremental changes in the teachers' practices also led to significant shifts in their professional attitudes. Although no explicit efforts were made to change teachers' relations to their teaching subjects, these relations began to change in unforced ways. The changes came about as teachers found themselves relying progressively less on textbooks and ready-made curriculum materials and began to devise, to use, and to share their own pedagogical resources. The use of interactive information and communication technologies, already familiar to most students, featured prominently in this connection (LA, 28-34 and 55-57).

Where teachers pursued new approaches with students over an extended period, changes in learning environments were sometimes striking, including regular features such as a readiness on students' part to ask questions, to venture an answer that might be wrong, to accept ideas and correction from other students, and to propose suggestions for project work and homework ( $L A, 45-46,48-49,51$, and 54). School leaders reported that where small-scale changes were succeeding and gathering some momentum, opportunities were created to expand the scope of developments so as to influence the learning environment of their schools more widely $(L A, 17-19)$. Taking advantage of such opportunities was the chief concern of the leadership dimension of the project, and this is even more the case now in the work of the TL21 Transfer Initiative with a larger number of schools.

Third, in order to engage with and strengthen teachers' capabilities, regular CPD workshops for teachers were a central feature of this research project. But these workshops themselves had a number of distinguishing features. They included expectations for active participation, clearly defined learning tasks, purposeful collaboration on these tasks, continuity between workshops in a developmental sequence, and feedback and evaluation during and between workshops 
(LA, 100). The kinds of learning communities that such features promoted modeled in practice the venturesome learning environments aimed for by the project as a whole. They also nurtured teachers' confidence and capacity to pursue similar aims in their own classrooms. This enabling momentum in teachers' self-understanding - from being reliable but largely acquiescent followers toward becoming perceptive and cooperative critics of their own practice - is probably the most significant of the project's achievements to date. The reasons for this are important and call now for some closer, but necessarily concise analysis.

Even when supported by convincing evidence from schools, findings such as these can fail to catch the attention of policymakers unless accompanied by some strategies that bring policymakers themselves into the practical research arena. Mindful of this issue, those involved with the TL21 project gathered a representative range of video recordings from classrooms and school laboratories and from interviews with students, teachers, and school principals. These were first presented at a colloquium and exhibition at NUIM in June 2007 to illustrate and review the kinds of developments that were taking place in the schools. Two further such events took place in May 2008 and June 2012, along with periodic bilateral meetings with interested parties in the intervals. Such parties included policymakers, managerial bodies, teacher union leaders, key figures from the National Council for Curriculum and Assessment, the schools' inspectorate, as well as principals and teachers from participating schools, and they attended these colloquia in large numbers. They watched evidence in the form of DVD clips from school classrooms and laboratories; they viewed exhibitions of students' work; they spoke informally to teachers; and they participated more formally in plenary presentation-and-discussion sessions.

And here the research team discovered an unexpected finding. Because such colloquia in themselves help to build learning relations, notably between researchers and policymakers, they are a productive way to advance - and to enlighten - the idea of evidence-informed policy. This idea contrasts with the controversial and sometimes coercive idea of "evidence-based" policy. ${ }^{22}$ The former's emphasis on colloquia and exhibitions, on giving voice to students, teachers, school leaders, and others, invites policymakers into a world they all too rarely experience - namely, the fuller dimensions of a research-friendly practitioners' world. An evidence-informed approach such as we have embraced does not eschew quantitative analysis; rather, it finds the proper use of such analysis crucial for accurate evaluation and assessment. But from the outset its understanding of capabilities — both of teachers and students - remains inseparable from viewing educational purposes as things to be reviewed, revised, and enhanced in the light of practitioners' own capable monitoring of practical research initiatives.

22. An illuminating critique of "evidence-based" policy is presented in Gert Biesta, Good Education in an Age of Measurement: Ethics, Politics, Democracy (Boulder, Colorado: Paradigm Publishers, 2010), chap. 2. 
The substantial success achieved by our colloquia, and by the idea of researchinformed policy that the colloquia helped to advance, is of course encouraging. It gives reason to hope that, by pursuing educational research along the lines described in this essay, progress might be made in promoting the notion of venturesome learning environments as a policy priority in a country's national educational policy. Hand-in-hand with this go brighter hopes for promoting CPD networks that enable teachers and students to become proficient in the kinds of relations of learning that we have been exploring. But such hopes can never be taken for granted. At their heart lies the conviction - to many politicians an audacious one - that education is a practice in its own right with its own inherent purposes. The dominant tenor of educational reform in most Western countries in recent decades indicates a contrary view. ${ }^{23}$ For the most part, reform measures have been curiously blind to the importance of relations in learning. They have routinely ignored the experienced quality of learning and have effectively made teachingto-the-test the mainstay of educational practice. Far from cultivating creative approaches among teachers, they have tended to homogenize and standardize teaching itself. Far from making learning environments places where it is safe to venture an idea that might be wrong, or where different imaginative neighborhoods might be frequently opened up, such environments are made conducive to conformity and prone to individualism.

Despite the recurring ineffectiveness of such remedies, they manifest a populist plausibility that makes them attractive to governments. In the United States, for instance, the staying power of the controversial No Child Left Behind initiative of 2001 and the propagation of the Race to the Top initiative of 2009 reveal this plausibility. Although the latter carries a more positive thrust than the former, both treat educational practitioners, including school leaders, as servile operatives to be controlled by carrot-and-stick in delivering targets imposed from above. Insightful educational debate becomes largely redundant in such circumstances.

But more promising alternatives, with a more convincing warrant and a more learner-centered focus, have now begun to make news internationally. Notable here is the "Fourth Way" thinking that Andy Hargreaves and Dennis Shirley have reported and analyzed in the last few years. ${ }^{24}$ A striking work is Pasi Sahlberg's recently published Finnish Lessons on the underlying reasons for Finland's prominence among the current educational success stories of Western democracies. ${ }^{25}$ Central to such approaches is the placing of trust in teachers and the promotion of participatory and purposeful learning among students. Classical ancestors of such alternatives can of course be found in the kinds of learning environments cultivated by Socrates in ancient Athens and memorably captured

23. See Andy Hargreaves and Dennis Shirley, The Fourth Way: The Inspiring Future for Educational Change (Thousand Oaks, California: Corwin Press, 2009); and Pasi Sahlberg, Finnish Lessons: What Can the World Learn from Educational Change in Finland? (New York: Teachers College Press, 2011).

24. Hargreaves and Shirley, The Fourth Way.

25. Sahlberg, Finnish Lessons. 
in the early dialogues of Plato. ${ }^{26}$ But the enormous promise of such pedagogical thinking and action was decisively and continually eclipsed by the forces of empire, church, and state over two millennia of Western civilization. The eclipse was not total however. There have been many distinguished if diverse figures who explored some variants of such promise - in their actions, in their writings, or in both - in the educational history of the West. Here one could broadly speak of an educational tradition that includes Heloise and her teacher Abelard in the twelfth century; ${ }^{27}$ Erasmus and Montaigne in the sixteenth; Vico, Rousseau, and Kant in the eighteenth; Pestalozzi, Froebel, and Peabody in the nineteenth; and Dewey and Freire in the twentieth.

\section{CONCLUSION}

Rearticulating the promise of this variegated but coherent educational tradition for the pluralist circumstances of the twenty-first century can only begin with a manifold recognition. Such a recognition underlies the arguments on relations of learning and environments of learning that have been made throughout this essay. More specifically, the recognition in question is a threefold one that makes explicit at the policy level what a commitment to venturesome learning environments involves at the practitioner level. First, there is the recognition that education is a primary and public good in a democratic society, as distinct from an ancillary service to the economy or to the current government in power. Second, there is the recognition that teaching is a practice - or family of practices - in its own right, as distinct from a subordinate range of activities to be controlled in all essentials by a body of superiors. That this practice must be accountable to democratic society is intrinsic to such recognition, but accountable for fruits that are genuinely of the practice itself, which is quite a distinct matter from acquiescence in externally imposed demands. Third, there is the recognition that the first and enduring priority of educational practice is to enhance the quality of human experiences of learning. Such an undertaking seeks to evoke and nourish the potentials of each student in communal, pluralist learning environments that develop the potentials from inheritances of learning, old and new.

26. These early dialogues include the Gorgias, the Protagoras, the Apology, the Crito, and the Republic (book 1).

27. In his biography of Abelard, Michael T. Clanchy draws on a number of scholarly sources to suggest that the young Heloise (in her mid- to late teens), far from being a docile student of Abelard's, made her own contributions to a stimulating learning environment and may have contributed significantly to Abelard's learning. Clanchy also makes the following thought-provoking comment on the removal of Heloise to a nunnery: "What could not be tolerated was her moving in next door with 'Master' Abelard as his lawful wife and equal in learning. More significant in its consequences for European culture than the castration and persecution of Abelard was the silencing of Heloise, as that was the prelude to the silencing of academic women as a class for the next eight centuries." Michael T. Clanchy, Abelard: A Medieval Life (Oxford: Blackwell, 1997), 46. 